\title{
Acute Symptoms after a Community Hydrogen Fluoride Spill
}

\author{
Joo-Yong Na, Kuck-Hyun Woo, Seong-Yong Yoon, Seong-Yong Cho, In-Ung Song, Joo-An Kim and Jin-Seok Kim
}

\begin{abstract}
Objectives: This study was conducted to describe the demographic characteristics, and clinical signs and symptoms of patients who visited a general hospital because of the release of chemically hazardous hydrogen fluoride that occurred on September 27, 2012 in Gumi City, Korea.

Methods: The medical records at 1 general hospital $9 \mathrm{~km}$ from the accident site were reviewed using a standardized survey format. There were 1,890 non-hospitalized and 12 hospitalized patients exposed to hydrogen fluoride between September 27 and October 132012.

Results: Among the 12 hospitalized patients, 11 were discharged within 1 week and the other was hospitalized for 10 days. The chief complaints were respiratory symptoms such as hemoptysis and shortness of breath,

gastrointestinal symptoms, neurologic symptoms, sore throat, and lip burn.

The number of non-hospitalized patients exhibited a bimodal distribution, peaking on the first and twelfth days after the accident. Their chief complaints were sore throat (24.1\%), headache (19.1\%), cough (13.1\%), and eye irritation (9.2\%); some patients were asymptomatic (6.2\%). Patients who visited the hospital within 3 days (early patients) of the spill more often had shortness of breath (27.0\%) and nausea (6.3\%) as the chief complaints than patients who visited after 3 days (late patients) (3.5\% and 2.6\%, respectively). However, cough and rhinorrhea were more common in the late patients (14.0\% and 3.3\%, respectively) than in the early patients $(5.0 \%$ and $0.0 \%$, respectively). Patients who were closer to the accident site more often had shortness of breath and sputum as the chief complaints than patients who were farther away. The mean serum calcium concentration was $9.37 \mathrm{mg} / \mathrm{dL}$ (range: 8.4-11.0 mg/dL); none of the patients had a decreased serum calcium level. Among 48 pulmonary function test results, 4 showed decreased lung function. None of the patients had abnormal urine fluoride levels on the eighth day after exposure.
\end{abstract}

Conclusions: Patients hospitalized due to chemical hazard release of hydrogen fluoride had acute respiratory, gastrointestinal, and neurologic health problems. Non-hospitalized patients have acute symptoms mainly related to upper respiratory irritation.

Keywords: Hydrofluoric acid, Chemical hazard release, Signs and symptoms

\section{Introduction}

Hydrogen fluoride is a highly hydrophilic and corrosive irritant that may cause burns to the skin and eyes and may damage the upper respiratory tract and lungs when inhaled. Hydrogen fluoride and its aqueous solution, hydrofluoric acid, can infiltrate the body via all exposure routes. It is less acidic than inorganic acids such as hydrogen chloride and hydrogen sulfide. However, its

\footnotetext{
* Correspondence: kjsoem@hanmail.net

Department of Occupational and Environmental Medicine, Soonchunhyang

University Gumi Hospital, 179, Gongdan 1-dong, Gumi-si, Gyeongbuk 730-706, Korea
}

high permeability can be fatal and cause deep tissue damage after a certain period of time from the initial contact with skin [1-6]. The most representative chronic toxicities of hydrogen fluoride are osteofluorosis and dental fluorosis, which involve the deposition of fluoride in the bones and teeth in people constantly consuming fluoride-contaminated drinking water or in workers performing aluminum smelting who are chronically exposed to hydrogen fluoride $[7,8]$. Hydrogen fluoride has been used in glasswork since the 17th century and is currently used in the manufacturing of high-octane 
gasoline for aviation fuel, metal plating, and hightemperature surface processing as well as in the production of plastics and refrigerants. In particular, hydrogen fluoride is capable of etching glass and metals, which prompts its widespread use in the semiconductor industry and in the manufacturing of electronic displays [1,9].

On September 27, 2012 at 3:40 pm, a hydrogen fluoride spill occurred in a hydrogen fluoride manufacturing plant located in Gumi City while 100\% hydrogen fluoride (anhydrous hydrofluoric acid) was being transferred from a hydrogen fluoride tanker truck to a storage tank. An estimated 8-12 tons of hydrogen fluoride was leaked over approximately $8 \mathrm{~h}$ until the tank spill was completely stopped. This accident killed 5 workers on site and hydrogen fluoride spread through the air, damaging the health of local residents and industrial workers as well as crops and other facilities [10].

The accident site was located at the fourth complex of the Gumi National Industrial Complex; local residents lived within a $2 \mathrm{~km}$ radius (Figure 1). According to the Gumi municipal accident report, the estimated time of the accident was 3:40 pm. The first evacuation notice was issued to the residents living within a $1.5 \mathrm{~km}$ radius around 4:50 pm, followed by an evacuation order for all residents living within a $1.3 \mathrm{~km}$ radius at 8:20 pm. According to the report of the Gumi Municipal Government [10], the atmospheric hydrogen fluoride concentration at the accident site was first measured $8 \mathrm{~h}$ after the accident and was $1 \mathrm{ppm}$. However, the second measurement, which was conducted at the accident site $5 \mathrm{~h}$ later, did not detect hydrogen fluoride in the atmosphere or nearby residential areas. The results of the initial water and soil quality standard tests conducted on October 1 and 2 were both below the thresholds for concern $(1.5 \mathrm{mg} / \mathrm{L}$ for water quality [11] and $400 \mathrm{mg} / \mathrm{kg}$ for soil quality [12]); subsequent tests also revealed the levels to be below the threshold values [13].

This study described and analyzed the demographic and clinical characteristics of patients who were treated at a general hospital for symptoms related to hydrogen fluoride exposure after the accident. In addition, we present the treatment experience of the outpatient clinic of the Department of Occupational and Environmental Medicine.

\section{Materials and methods}

A total of 6,982 people were treated at a private medical institution for physical symptoms caused by the hydrogen

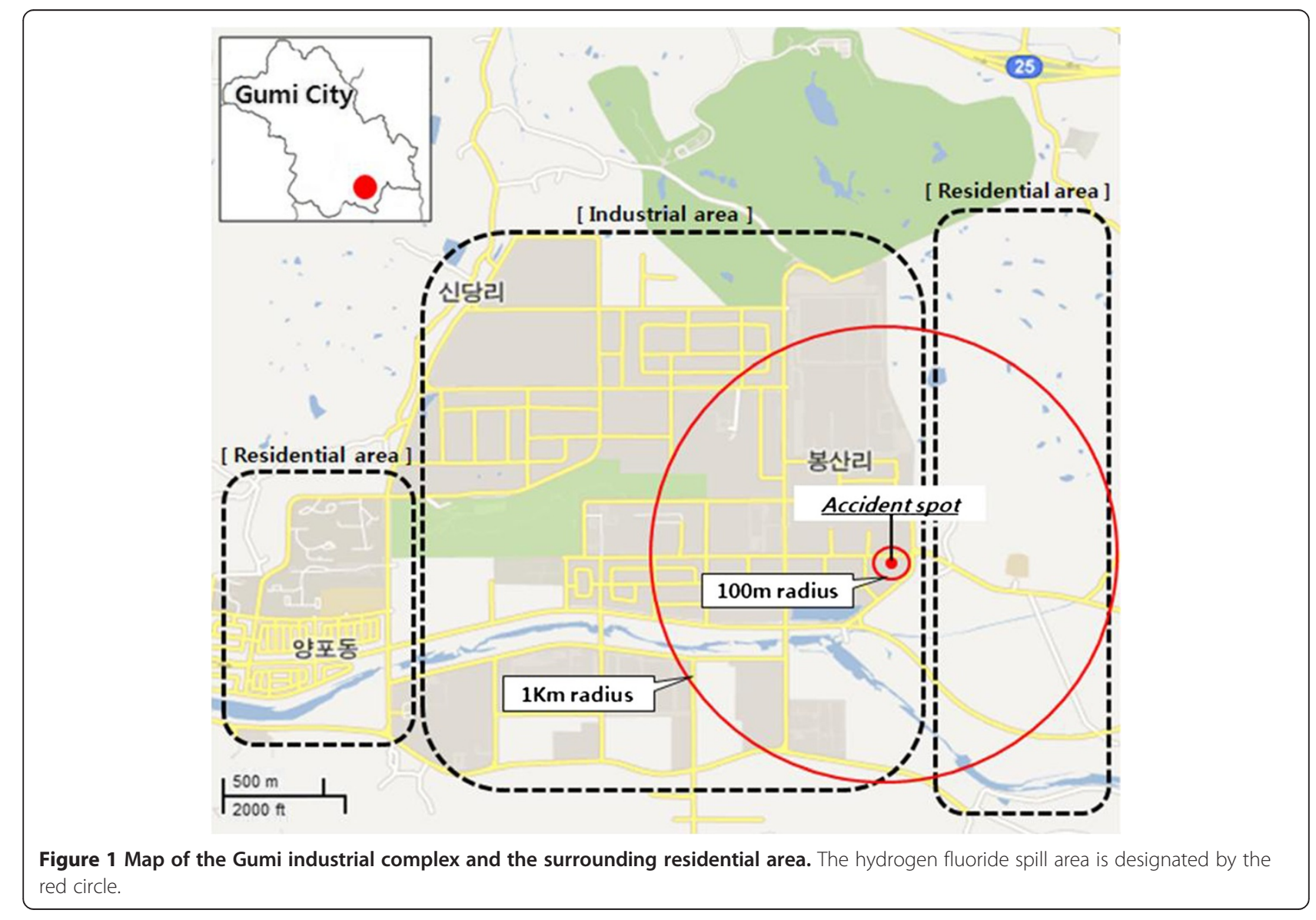


fluoride spill from September 27 to October 21, 2012, and an additional 5,261 people visited the temporary on-site clinic provided by the Gumi Municipal Government; thus, a total of 12,243 people were treated for fluoride-related symptoms [10]. Among the 3 general hospitals near the accident site, this study analyzed patients treated for hydrogen fluoride exposure at a university hospital located approximately $9 \mathrm{~km}$ from the accident site. A total of 1,952 outpatients visited the university hospital over 17 days from the start of the accident (from September 27 to October 13, 2012) because of symptoms related to hydrogen fluoride exposure, including 3 people who died. There were 10 hospitalized patients during the same period, and an additional 2 were hospitalized after October 14, resulting in a total of 12 hospitalized patients. Medical records and questionnaires completed at the time of outpatient treatment of these patients were reviewed by 7 clinicians at the Department of Occupational and Environmental Medicine using the same survey method. A total of 1,952 outpatients were surveyed; $1,890(96.8 \%)$ were included in the final analysis after excluding the 62 patients for whom medical records were unavailable.

A questionnaire survey was conducted on the exposure characteristics and symptoms. But, the survey was not conducted at the emergency clinic, because the questionnaire could not be prepared. Outpatients who attended 6 days after the accident occurred were surveyed through a self-completed questionnaire. When completing the survey, prior consent was obtained using a consent form for the collection and use of personal information. The surveyed content included basic demographic information (e.g., occupation and residence), exposure characteristics after the spill (e.g., distance from the accident site and location other than indoors), main symptoms, accompanying symptoms, medical history, physical examination findings, prescriptions, and second visits.

During outpatient visits at the Department of Occupational and Environmental Medicine, regular blood tests, liver function index tests, electrolyte tests including serum calcium, chest radiographs, pulmonary function tests, and urine fluoride concentration tests were performed with patient consent. No tests were performed on patients who were asymptomatic, showed mild symptoms, or did not provide consent. Many patients who initially visited the hospital through the emergency room received treatment simultaneously and required immediate calcium gluconate inhalation therapy and eye wash treatment. Therefore, information regarding exposure, symptoms, and clinical test results could not be identified through the medical records of the majority of the patients who initially visited the emergency room.

Urine fluoride was measured as a biological index of exposure to quantify individual exposure. Immediately after the spill, there were no institutions in Korea that could immediately perform fluoride analysis. On October 5 (the eighth day after the spill), a urine fluoride analysis device was ordered. Sixty-six patients suspected of having been exposed to relatively high concentrations of hydrogen fluoride among the 217 patients who visited on that day were selected; these patients included 46 workers who normally worked at an office within $100 \mathrm{~m}$ of the accident site even after the spill and 20 patients who were arbitrarily selected by clinicians because of their severe symptoms. Urine samples were stored in a freezer at $-20^{\circ} \mathrm{C}$ and analyzed using a fluoride-ion specific electrode analyzer (Orion Star A214, Thermo Fisher Scientific Inc., Japan) when analysis was possible after 2 weeks.

With respect to the occupations, the patients were classified as local residents, workers, firefighters, police, public officials, and others. Local residents were further classified into adjacent residents and other residents. Adjacent residents included those from the 2 villages close to and downwind of the accident site that suffered direct damage to crops and facilities. The rest were classified as other residents. Depending on the time of the hospital visit, those who visited within 3 and after 4 days of the accident were classified as early and late patients, respectively. In addition, the distance to the accident site was classified as within $100 \mathrm{~m}$, from $100 \mathrm{~m}$ to $1 \mathrm{~km}$, and over $1 \mathrm{~km}$.

Data were analyzed using SPSS version 14 (SPSS, Inc., Chicago, IL, USA). The $\chi^{2}$ test and t-test were used for simple analyses, while $X^{2}$ trend analysis was used to analyze differences in symptoms and complaints with respect to the distance from the accident site. Analysis of variance (ANOVA) and analysis of covariance (ANCOVA) adjusted for age and sex were used to compare clinical parameters.

\section{Results}

A total of 12 patients were hospitalized owing to hydrogen fluoride exposure. Among them were 5 residents in the nearby area, 4 workers, 2 other residents, and 1 public officer. Eleven patients showed improvement after appropriate treatment and were discharged within 1 week, but 1 patient who was admitted on October 16 was hospitalized for 10 days. The chief complaints of the hospitalized patients were respiratory symptoms such as hemoptysis and dyspnea; gastrointestinal symptoms including nausea and indigestion; neurologic symptoms such as headache and numbness; sore throat; and lip pain. Three patients hospitalized due to hemoptysis presented with redness and edema in the bronchial mucosa and rebleeding during washing on bronchoscopy. However, they were discharged after several days of conservative treatment. The 2 patients who complained of gastrointestinal symptoms presented with ulcers and chronic atrophic 
gastritis, respectively, during endoscopic examination but were discharged when they showed improvement after medication. The patient who was hospitalized at the otorhinolaryngology department because of findings of acute throat injection was discharged after medication. No specific abnormalities were found on physical examinations or by clinical tests in the patients hospitalized in the respiratory and neurology departments for symptoms such as shortness of breath, headache, and numbness in the hands and feet; these patients were discharged after receiving conservative treatment for their symptoms (Table 1).

Regarding the distribution of time of hospital visits, 10 patients visited on the day of the accident (September 27) through the emergency room, followed by 157 and 9 patients on the first and second days after the accident, respectively. No patients visited the hospital on the third day after the accident (September 30), which was the Chuseok Holiday. From the fifth day after the accident, the number of visiting patients increased to 33, reaching 217 on the eighth day, decreasing to 70 on the tenth day, and then decreasing again after reaching a peak of 235 patients on the twelfth day (Figure 2).

Regarding the age distribution of the outpatients, the largest proportion of patients were in their $30 \mathrm{~s}(30.4 \%)$ followed by patients in their $40 \mathrm{~s}$ (21.2\%), $20 \mathrm{~s}$ (17.9\%), and those aged $<9$ years (5.8\%). Men accounted for $52.8 \%$ of all patients. The departments that provided the initial treatment were occupational and environmental medicine
(80.8\%), pediatrics $(7.2 \%)$, internal medicine $(6.9 \%)$, emergency medicine $(2.9 \%)$, ophthalmology $(1.1 \%)$, and otorhinolaryngology $(0.6 \%)$. Among the patients exposed to hydrogen fluoride, the largest proportion were residents (42.7\%), with $11.2 \%$ and $31.5 \%$ of patients representing nearby and other residents, respectively; workers, police and public officials, and firefighters accounted for 39.9\%, $3.6 \%$, and $2.1 \%$ of the patients, respectively. At the time of the accident, $80.4 \%$ and $19.1 \%$ of the patients exposed to hydrogen fluoride were indoors and outdoors, respectively. A total of $176(9.3 \%)$ patients visited the hospital within 3 days of the accident, while 1,714 (90.7\%) visited 4 days after the accident, and these patients were classified as early and late patients, respectively. Regarding the distance from the accident site, $14.6 \%, 46.5 \%$, and $38.9 \%$ of patients were within $100 \mathrm{~m}, 100 \mathrm{~m}$ to $1 \mathrm{~km}$, and over $1 \mathrm{~km}$, respectively, from the accident site (Table 2).

The chief complaints reported by the patients were sore throat (24.1\%), headache (19.1\%), cough (13.2\%), and eye irritation $(9.2 \%) ; 6.2 \%$ of the patients were asymptomatic. The prevalence of shortness of breath was higher among early patients $(27.0 \%)$ than among late patients $(3.5 \%)$; nausea was also more prevalent in the early patients (6.3\%) than the late patients $(2.6 \%)$. In contrast, cough was more prevalent in the late patients $(19.4 \%)$ than the early patients (5.0\%). Moreover, there were more asymptomatic patients among the late patients $(6.4 \%)$ than the early patients $(3.8 \%)(\mathrm{p}<0.05)$ (Table 3$)$.

Table 1 Details of the 12 hospitalized patients

\begin{tabular}{|c|c|c|c|c|c|c|c|c|}
\hline Age & Gender & Department & $\begin{array}{l}\text { Date of } \\
\text { admission }\end{array}$ & $\begin{array}{l}\text { Date of } \\
\text { discharge }\end{array}$ & $\begin{array}{l}\text { Chief } \\
\text { complaints }\end{array}$ & Diagnosis & Exposure characteristics & Clinical findings \\
\hline 30 & M & $\mathrm{IP}^{\dagger}$ & $9 / 28$ & $9 / 29$ & Dyspnea & Gas inhalation & Worker & No abnormal findings \\
\hline 51 & $\mathrm{~F}$ & $\mathbb{I P}$ & $10 / 3$ & $10 / 10$ & Hemoptysis & Bronchitis & Adjacent resident & $\begin{array}{l}\text { Bronchoscopy ; hyperemic, } \\
\text { both bronchi edematous }\end{array}$ \\
\hline 52 & $M$ & $\mathbb{I P}$ & $10 / 3$ & $10 / 8$ & $\begin{array}{l}\text { Blood-tinged } \\
\text { sputum }\end{array}$ & Bronchitis & Governmental officials & $\begin{array}{l}\text { Bronchoscopy ; both bronchi } \\
\text { hyperemic }\end{array}$ \\
\hline 44 & $\mathrm{~F}$ & $\mathbb{I P}$ & $10 / 9$ & $10 / 12$ & Dyspnea & Gas inhalation & Worker & No abnormal findings \\
\hline 52 & $\mathrm{~F}$ & $\mathbb{I P}$ & $10 / 16$ & $10 / 25$ & Dyspnea & $\begin{array}{l}\text { Toxic effect of } \\
\mathrm{HF}^{*}\end{array}$ & Adjacent resident & Anxiety \\
\hline 38 & $M$ & $\mathbb{I P}$ & $10 / 24$ & $10 / 26$ & Hemoptysis & Bronchitis & Worker & $\begin{array}{l}\text { Bronchoscopy ; both bronchi } \\
\text { hyperemic }\end{array}$ \\
\hline 44 & $\mathrm{~F}$ & $\mathrm{IG}^{\ddagger}$ & $10 / 6$ & $10 / 10$ & Nausea & Gastric ulcer & Adjacent resident & $\mathrm{GIF}^{++}$; gastric ulcer \\
\hline 68 & $\mathrm{~F}$ & IG & $10 / 9$ & $10 / 12$ & Nausea & Gas inhalation & Adjacent resident & GIF; chronic atropic gastritis \\
\hline 25 & $\mathrm{~F}$ & $\mathrm{ENT}^{\S}$ & $10 / 6$ & $10 / 11$ & Sore throat & $\begin{array}{l}\text { Acute } \\
\text { pharyngotonsillitis }\end{array}$ & Worker & Pharyngeal injection \\
\hline 57 & $\mathrm{~F}$ & NR $R^{\| 1}$ & $10 / 4$ & $10 / 8$ & Numbness & Numbness & $\begin{array}{l}\text { Other resident (Intake of } \\
\text { contaminated crops) }\end{array}$ & No abnormal findings \\
\hline 79 & $\mathrm{~F}$ & NR & $10 / 9$ & $10 / 12$ & Headache & $\begin{array}{l}\text { Chronic tension } \\
\text { headache }\end{array}$ & Adjacent resident & No abnormal findings \\
\hline 71 & $\mathrm{~F}$ & $P S^{* *}$ & $10 / 8$ & $10 / 8$ & Lip pain & $\begin{array}{l}\text { Chemical burn on } \\
\text { lower lip }\end{array}$ & $\begin{array}{l}\text { Other Resident (intake of } \\
\text { contaminated crops) }\end{array}$ & $\begin{array}{l}\text { Swelling, erythema on lower } \\
\text { lip }\end{array}$ \\
\hline
\end{tabular}

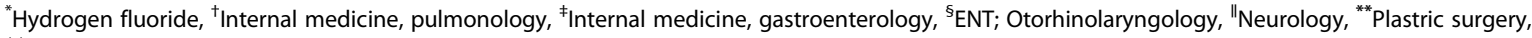

${ }^{++}$Gastro-intestinal fiberscopy. 


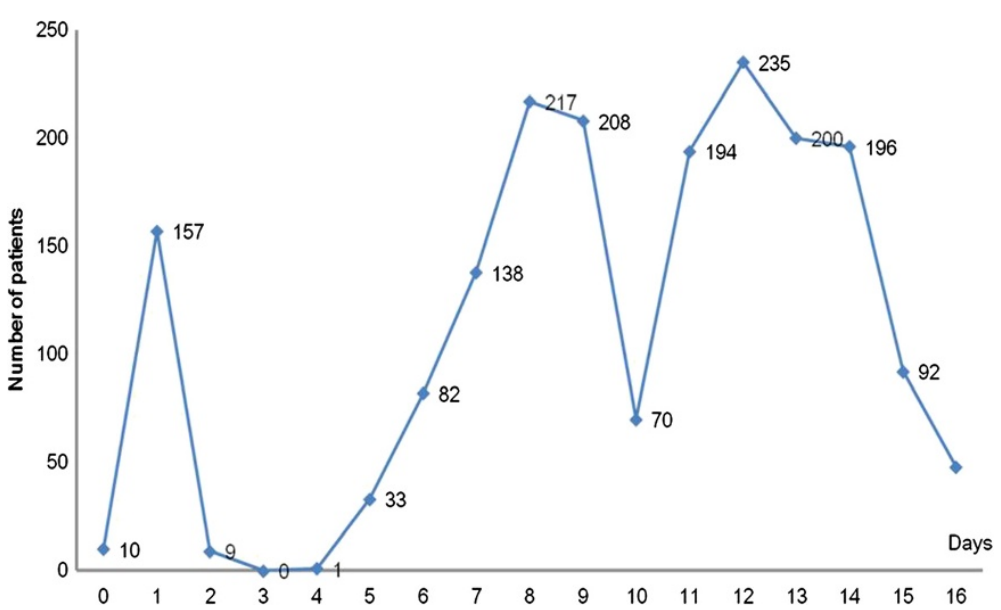

Figure 2 Distribution of numbers of non-hospitalized patients by day.

Regarding individual symptom complaints other than chief complaints, the most common complaints were cough $(43.3 \%)$, sore throat (42.6\%), and headache (41.9\%). Shortness of breath was observed in $30.7 \%$ of the early patients but in only $14.7 \%$ of the late patients. Cough $(15.3 \%$ and $46.1 \%$ in the early and late patients, respectively), headache (26.7\% and $43.5 \%)$, eye irritation (19.9\% and $31.3 \%)$, dizziness (5.1\% and $15.2 \%)$, and skin rash $(0.6 \%$ and $3.8 \%)$ were more prevalent in the late patients (Table 4).

The patients' characteristics were compared with respect to their distance from the accident site (i.e., within $100 \mathrm{~m}$, $100 \mathrm{~m}$ to $1 \mathrm{~km}$, and over $1 \mathrm{~km}$ ). There were more men near the accident site: $18.3 \%$ of men were within $100 \mathrm{~m}$ compared to $10.6 \%$ of women. Regarding age, $63.3 \%$ of patients aged $<19$ years were located over $1 \mathrm{~km}$ away, while $11.8 \%$ and $21.2 \%$ of those aged $20-39$ and $40-59$ years were located within $100 \mathrm{~m}$, respectively. Regarding those aged 60 years and over, $72.8 \%$ were located from $100 \mathrm{~m}$ to $1 \mathrm{~km}$ from the accident site. Regarding exposure characteristics, nearby residents accounted for a substantial number of patients, as $79.7 \%$ were located from $100 \mathrm{~m}$ to $1 \mathrm{~km}$ from the accident site, while $73.7 \%$ of the other residents were located over $1 \mathrm{~km}$ away. Regarding workers, $14.8 \%$ and $58.5 \%$ were within $100 \mathrm{~m}$ and from $100 \mathrm{~m}$ to $1 \mathrm{~km}$, respectively. Among the early and late patients, $52.9 \%$ and $12.8 \%$ were within $100 \mathrm{~m}$, respectively.

Physical examination findings were analyzed with respect to the distance from the accident site. Abnormal pulmonary sound was more common in patients closer to the site: $7.4 \%, 2.5 \%$, and $1.0 \%$ were within $100 \mathrm{~m}$, from $100 \mathrm{~m}$ to $1 \mathrm{~km}$, and over $1 \mathrm{~km}$ away, respectively, from the site. Skin abnormalities were also common in the patients closer to the site: $9.7 \%, 6.7 \%$, and $3.5 \%$ were within $100 \mathrm{~m}$, from $100 \mathrm{~m}$ to $1 \mathrm{~km}$, and over $1 \mathrm{~km}$ away, respectively, from the site. Among the 48 patients administered the pulmonary function test, 4 exhibited abnormal findings; however, there was no significant association with exposure distance (Table 5).

Upon analyzing the chief complaints with respect to distance, shortness of breath was found in $8.0 \%, 4.2 \%$, and $3.4 \%$ of patients within $100 \mathrm{~m}$, from $100 \mathrm{~m}$ to $1 \mathrm{~km}$, and over $1 \mathrm{~km}$ away, respectively, from the site. In contrast, no symptoms and rhinorrhea were more common with increasing distance from the accident site. No symptoms were observed in $1.8 \%, 3.6 \%$, and $6.1 \%$ of patients within $100 \mathrm{~m}$, from $100 \mathrm{~m}$ to $1 \mathrm{~km}$, and over $1 \mathrm{~km}$ away, respectively, from the site. Meanwhile, rhinorrhea was observed in $0.9 \%, 1.9 \%$, and $4.7 \%$ of patients within $100 \mathrm{~m}$, from $100 \mathrm{~m}$ to $1 \mathrm{~km}$, and over $1 \mathrm{~km}$ away, respectively, from the site (Table 6).

Regarding the results of the blood tests and clinical chemistry tests, RBC, hematocrit, phosphorus, potassium, r-GTP, ALP, glucose, blood urea nitrogen, creatinine, and uric acid differed significantly according to the distance from the accident site. However, after adjusting for age and sex, the differences were only significant for hematocrit, potassium, and glucose. Blood hematocrit values increased with decreasing distance, with the values being $44.1 \pm 4.44 \%, 43.5 \pm 4.25 \%$, and $41.9 \pm$ $4.15 \%$ in patients within $100 \mathrm{~m}$, from $100 \mathrm{~m}$ to $1 \mathrm{~km}$, and over $1 \mathrm{~km}$ away, respectively. Potassium levels also increased with decreasing distance, with the levels being $4.13 \pm 0.34,4.07 \pm 2.03$, and $4.04 \pm 0.28 \mathrm{mmol} / \mathrm{L}$ in $\mathrm{pa}-$ tients within $100 \mathrm{~m}$, from $100 \mathrm{~m}$ to $1 \mathrm{~km}$, and over $1 \mathrm{~km}$ away, respectively. Glucose levels also increased with decreasing distance, with the levels being $113.0 \pm 48.5$, $105.5 \pm 32.9$, and $100.1 \pm 20.9 \mathrm{mg} / \mathrm{dL}$ in patients within $100 \mathrm{~m}$, from $100 \mathrm{~m}$ to $1 \mathrm{~km}$, and over $1 \mathrm{~km}$ away, respectively ( $\mathrm{p}<0.05$ ) (Table 7 ).

Calcium concentration was measured in 1,284 outpatients. The mean of the measured values was $9.37 \mathrm{mg} / \mathrm{dL}$ 
Table 2 General characteristics of non-hospitalized patients

$$
\begin{gathered}
\hline \text { Characteristic } \\
\hline \text { Age(years) } \\
0-9 \\
10-19 \\
20-29 \\
30-39 \\
40-49 \\
50-59 \\
\geq 60
\end{gathered}
$$

Gender

$$
\begin{aligned}
& \text { Male } \\
& \text { Female }
\end{aligned}
$$

First visit to the outpatient department

Occupational and environmental
Pediatrics
Internal medicine, Pulmonology
Emergency medicine
Ophthalmologic medicine
Otorhinolaryngology
Others

Exposure characteristics

Adjacent residents

Other residents

Workers

Firefighters

Police and public officials

Others

Location at the time of the accident

Indoor

Others

Time of first hospital visit

Within 3 days

After 4 days

Distance from the place of the accident spot

Under $100 \mathrm{~m}$

$100 \mathrm{~m}-1 \mathrm{~km}$

Over $1 \mathrm{~km}$

(range: $8.4-11.0 \mathrm{mg} / \mathrm{dL}$ ). No patients had calcium levels below the threshold of $8.4 \mathrm{mg} / \mathrm{dL}$. The mean urine fluoride level of the 66 samples collected on the eighth day after the accident was $0.39 \pm 0.24 \mathrm{mg} / \mathrm{L}$ (range: 0.03-1.6 mg/L). All of the measurements were below

\begin{tabular}{|c|c|c|c|c|c|c|c|}
\hline \multirow[t]{2}{*}{ Chief complaint } & \multicolumn{2}{|c|}{$\begin{array}{c}\text { Early } \\
\text { patients }\end{array}$} & \multicolumn{2}{|c|}{$\begin{array}{c}\text { Late } \\
\text { patients }^{\dagger}\end{array}$} & \multicolumn{2}{|c|}{ Total } & \multirow[t]{2}{*}{$p$-value $e^{\ddagger}$} \\
\hline & $\mathbf{N}$ & $\%$ & $\mathbf{N}$ & $\%$ & $\mathbf{N}$ & $\%$ & \\
\hline Sore throat & 37 & 23.3 & 394 & 24.2 & 431 & 24.1 & 0.797 \\
\hline Headache & 25 & 15.7 & 316 & 19.4 & 341 & 19.1 & 0.260 \\
\hline Cough & 8 & 5.0 & 228 & 14.0 & 236 & 13.2 & 0.001 \\
\hline Eye irritation & 17 & 10.7 & 147 & 9.0 & 164 & 9.2 & 0.487 \\
\hline No symptom & 6 & 3.8 & 105 & 6.4 & 111 & 6.2 & 0.183 \\
\hline Shortness of breath & 43 & 27.0 & 57 & 3.5 & 100 & 5.6 & 0.000 \\
\hline Chest pain & 3 & 1.9 & 63 & 3.9 & 66 & 3.7 & 0.206 \\
\hline Dizziness & 2 & 1.3 & 54 & 3.3 & 56 & 3.1 & 0.155 \\
\hline Nausea & 10 & 6.3 & 43 & 2.6 & 53 & 3.0 & 0.010 \\
\hline Rhinorrhea & 0 & 0.0 & 53 & 3.3 & 53 & 3.0 & 0.021 \\
\hline Skin burning & 2 & 1.3 & 36 & 2.2 & 38 & 2.1 & 0.427 \\
\hline Itching & 0 & 0.0 & 32 & 2.0 & 32 & 1.8 & 0.075 \\
\hline Sputum & 1 & 0.6 & 26 & 1.6 & 27 & 1.5 & 0.340 \\
\hline Nasal pain & 1 & 0.6 & 14 & 0.9 & 15 & 0.8 & 0.761 \\
\hline Skin rash & 0 & 0.0 & 7 & 0.4 & 7 & 0.4 & 0.408 \\
\hline Vomiting & 0 & 0.0 & 2 & 0.1 & 2 & 0.1 & 0.658 \\
\hline Others & 4 & 2.5 & 52 & 3.2 & 56 & 3.1 & 0.640 \\
\hline Total & 159 & 100.0 & 1629 & 100.0 & 1788 & 100.0 & \\
\hline
\end{tabular}
$3 \mathrm{mg} / \mathrm{g} \mathrm{Cr}$, which is the pre-work exposure threshold

\begin{tabular}{|c|c|c|c|c|c|c|c|}
\hline & \multicolumn{2}{|c|}{$\begin{array}{c}\text { Early } \\
\text { patients }\end{array}$} & \multicolumn{2}{|c|}{$\begin{array}{c}\text { Late } \\
\text { patients }\end{array}$} & \multicolumn{2}{|c|}{ Total } & \multirow[t]{2}{*}{$p$-value $e^{\ddagger}$} \\
\hline & $\mathrm{N}$ & $\%$ & $\mathrm{~N}$ & $\%$ & $\mathbf{N}$ & $\%$ & \\
\hline Cough & 27 & 15.3 & 791 & 46.1 & 818 & 43.3 & 0.000 \\
\hline Sore throat & 64 & 36.4 & 741 & 43.2 & 805 & 42.6 & 0.079 \\
\hline Headache & 47 & 26.7 & 745 & 43.5 & 792 & 41.9 & 0.000 \\
\hline Eye irritation & 35 & 19.9 & 536 & 31.3 & 571 & 30.2 & 0.002 \\
\hline Nausea & 25 & 14.2 & 327 & 19.1 & 352 & 18.6 & 0.114 \\
\hline Shortness of breath & 54 & 30.7 & 252 & 14.7 & 306 & 16.2 & 0.000 \\
\hline Dizziness & 9 & 5.1 & 260 & 15.2 & 269 & 14.2 & 0.000 \\
\hline Chest pain & 5 & 2.8 & 102 & 6.0 & 107 & 5.7 & 0.089 \\
\hline Skin burning & 5 & 2.8 & 77 & 4.5 & 82 & 4.3 & 0.306 \\
\hline Skin rash & 1 & 0.6 & 65 & 3.8 & 66 & 3.5 & 0.027 \\
\hline Vomiting & 2 & 1.1 & 45 & 2.6 & 47 & 2.5 & 0.227 \\
\hline Total & 176 & 100.0 & 1714 & 100.0 & 1890 & 100.0 & \\
\hline
\end{tabular}

Table 3 Chief complaints of early and late patients

* Early patients: hospital visit within 3 days.

† Late patients: hospital visit 4 days or after.

‡ Chi-squared test.

Table 4 Symptom complaints of early and late patients

* Early patients: hospital visit within 3 days.

+ Late patients: hospital visit 4 days or after.

‡ Chi-squared test. 
Table 5 Patient characteristics with respect to distance from the accident site

\begin{tabular}{|c|c|c|c|c|c|c|c|}
\hline & \multicolumn{2}{|c|}{$\begin{array}{c}\text { Under } 100 \\
\mathrm{~m}\end{array}$} & \multicolumn{2}{|c|}{$100 \mathrm{~m}-1 \mathrm{~km}$} & \multicolumn{2}{|c|}{ Over 1 km } & \multirow[t]{2}{*}{ p-value ${ }^{*}$} \\
\hline & $N$ & $\%$ & $\mathrm{~N}$ & $\%$ & $\mathrm{~N}$ & $\%$ & \\
\hline Sex & & & & & & & 0.000 \\
\hline Male & 149 & 65.6 & 418 & 58.0 & 249 & 41.3 & \\
\hline Female & 78 & 34.4 & 303 & 42.0 & 354 & 58.7 & \\
\hline
\end{tabular}

$\begin{array}{lrrrrrr}\text { Under 19 } & 7 & 3.1 & 22 & 3.0 & 50 & 8.3 \\ 20 \sim 39 & 96 & 42.3 & 351 & 43.7 & 370 & 61.3 \\ 40 \sim 59 & 117 & 51.5 & 273 & 37.9 & 162 & 26.9 \\ \text { Over 60 } & 7 & 3.1 & 75 & 10.4 & 21 & 3.5\end{array}$

Exposure characteristics

$\begin{array}{lrrrrrrr}\begin{array}{l}\text { Adjacent } \\ \text { residents }\end{array} & 12 & 5.4 & 126 & 17.6 & 20 & 3.3 \\ \text { Other residents } & 12 & 5.4 & 103 & 14.4 & 323 & 53.7 \\ \text { Workers } & 103 & 46.6 & 408 & 56.9 & 187 & 31.1 \\ \text { Firefighters } & 19 & 8.6 & 1 & 0.1 & 3 & 0.5 \\ \text { Public officials } & 9 & 4.1 & 8 & 1.1 & 5 & 0.8 \\ \text { Others } & 66 & 29.9 & 71 & 9.9 & 64 & 10.6\end{array}$

Time of hospital visit

$\begin{array}{lrrrrrr}\text { Within 3 days } & 37 & 16.3 & 25 & 3.5 & 8 & 1.3 \\ 4 \text { days or after } & 190 & 83.7 & 696 & 96.5 & 595 & 98.7\end{array}$

Abnormal physical findings

$\begin{array}{lrrrrrrr}\text { Throat } & 72 / & 52.9 & 273 / & 58.6 & 204 / & 51.0 & 0.240 \\ & 136 & & 466 & & 400 & & \\ \text { Nose } & 10 / 80 & 12.5 & 25 / 248 & 10.1 & 16 / 223 & 7.2 & 0.126 \\ \text { Eye } & 12 / 82 & 14.6 & 35 / 250 & 14.0 & 25 / 242 & 10.3 & 0.202 \\ \text { Lung } & 7 / 95 & 7.4 & 8 / 326 & 2.5 & 3 / 303 & 1.0 & 0.001 \\ \text { Heart } & 0 / 92 & 0.0 & 0 / 294 & 0.0 & 0 / 292 & 0.0 & - \\ \text { Skin } & 7 / 72 & 9.7 & 15 / 225 & 6.7 & 8 / 229 & 3.5 & 0.002\end{array}$

Abnormal PFT

$\begin{array}{llllllll}\text { FVC\% }^{\dagger} & 2 / 14 & 14.3 & 1 / 27 & 3.7 & 1 / 7 & 14.3 & 0.739\end{array}$

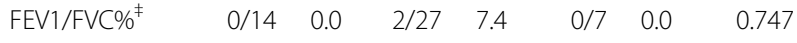

${ }^{*}$ Chi-squared test for trend.

${ }^{+}$Decreased FVC $<80 \%$.

${ }^{\ddagger}$ Decreased FVC/FEV1 ratio $<70 \%$.

provided by American Conference of Governmental Industrial Hygienists (ACGIH).

\section{Discussion}

Hydrogen fluoride is a potent irritant that exists in a colorless gaseous or transparent liquid state. Pure hydrogen fluoride exists in a gaseous form at room temperatures over $19.5^{\circ} \mathrm{C}[14,15]$. It is not explosive but generates heat when mixed with water; can react with metal, water, and steam; and can corrode silicon, glass, and concrete $[9,16]$. The Gumi spill involved 100\% hydrogen fluoride. The
Table 6 Chief complaints with respect to distance from the accident site

\begin{tabular}{|c|c|c|c|c|c|c|c|}
\hline & \multicolumn{2}{|c|}{$\begin{array}{l}\text { Under } \\
100 \mathrm{~m}\end{array}$} & \multicolumn{2}{|c|}{$100 \mathrm{~m}-1 \mathrm{~km}$} & \multicolumn{2}{|c|}{ Over 1 km } & \multirow[t]{2}{*}{ p-value* } \\
\hline & $\mathrm{N}$ & $\%$ & $\mathrm{~N}$ & $\%$ & $\mathrm{~N}$ & $\%$ & \\
\hline Sore throat & 51 & 22.7 & 195 & 28.2 & 131 & 23.5 & 0.660 \\
\hline Headache & 46 & 20.4 & 142 & 20.5 & 106 & 19.0 & 0.549 \\
\hline Cough & 27 & 12.0 & 87 & 12.6 & 82 & 14.7 & 0.234 \\
\hline Eye irritation & 21 & 9.3 & 58 & 8.4 & 47 & 8.4 & 0.742 \\
\hline Shortness of breath & 18 & 8.0 & 29 & 4.2 & 19 & 3.4 & 0.012 \\
\hline Chest pain & 11 & 4.9 & 33 & 4.8 & 18 & 3.2 & 0.190 \\
\hline Dizziness & 9 & 4.0 & 27 & 3.9 & 17 & 3.0 & 0.423 \\
\hline Nausea & 3 & 1.3 & 26 & 3.8 & 14 & 2.5 & 0.784 \\
\hline Rhinorrhea & 2 & 0.9 & 13 & 1.9 & 26 & 4.7 & 0.001 \\
\hline Skin burning & 5 & 2.2 & 13 & 1.9 & 16 & 2.9 & 0.405 \\
\hline Itching & 5 & 2.2 & 13 & 1.9 & 9 & 1.6 & 0.557 \\
\hline Sputum & 8 & 3.6 & 7 & 1.0 & 10 & 1.8 & 0.289 \\
\hline Nasal pain & 2 & 0.9 & 3 & 0.4 & 9 & 1.6 & 0.137 \\
\hline Skin rash & 1 & 0.4 & 4 & 0.6 & 0 & 0.0 & 0.169 \\
\hline Vomiting & 0 & 0.0 & 1 & 0.1 & 0 & 0.0 & 0.744 \\
\hline Others & 12 & 5.3 & 16 & 2.3 & 20 & 3.6 & 0.548 \\
\hline No symptom & 4 & 1.8 & 25 & 3.6 & 34 & 6.1 & 0.003 \\
\hline Total & 225 & 100.0 & 692 & 100.0 & 558 & 100.0 & \\
\hline
\end{tabular}

${ }^{*}$ Chi-squared test for trend.

fumes generated by the hydrogen fluoride combining with the moisture in the atmosphere were spread by the wind to adjacent areas, harming people, animals, and plants in the local community, as well as corroding buildings and cars due to their corrosive nature against metals and glass. Hydrogen fluoride which combines with the moisture in the mucous membranes of the human body can cause irritation first in the skin, eyes, and upper respiratory system including the nose and throat. Hydrogen fluoride gas is strongly hydrophilic and reactive in slightly acidic environments such as the body's physiological acidity (pKa: 3.45 ); therefore, gas inhaled through the oral or nasal cavities is mostly absorbed into the upper respiratory tract. Inhaling large amounts of hydrogen fluoride gas can cause interstitial pneumonia and pulmonary edema, because the gas is absorbed by the lower respiratory tract as well $[17,18]$. In addition, hydrogen fluoride accumulating in the capillary tracheae is discharged into the upper tract because of ciliary action and enters the gastrointestinal system where it is ultimately absorbed by the gastrointestinal tract. This can cause gastrointestinal symptoms such as nausea, vomiting, and heartburn $[14,16,17,19]$. In this study, the chief complaints of outpatients in descending order were sore throat, headache, cough, and eye irritation, which are consistent with upper respiratory tract infection irritation symptoms due to hydrogen fluoride [20]. Many 
Table 7 Laboratory results with respect to distance from the accident site

\begin{tabular}{|c|c|c|c|c|c|c|c|c|}
\hline & \multicolumn{2}{|c|}{ Under $100 \mathrm{~m}$} & \multicolumn{2}{|c|}{$100 \mathrm{~m}-1 \mathrm{~km}$} & \multicolumn{2}{|c|}{ Over 1 km } & \multirow{2}{*}{$\begin{array}{l}\text { Crude } \\
\text { p-value }\end{array}$} & \multirow{2}{*}{$\begin{array}{l}\text { Adjusted } \\
\text { p-value }\end{array}$} \\
\hline & $\mathbf{N}$ & Mean \pm SD & $\mathbf{N}$ & Mean \pm SD & $\mathbf{N}$ & Mean \pm SD & & \\
\hline \multicolumn{9}{|l|}{ Complete blood cell count } \\
\hline WBC $\left(\times 10^{3} / \mathrm{mm}^{3}\right)$ & 166 & $6.97 \pm 1.60$ & 488 & $7.11 \pm 1.97$ & 471 & $6.99 \pm 1.88$ & 0.548 & 0.500 \\
\hline $\mathrm{RBC}\left(\times 10^{6} / \mathrm{mm}^{3}\right)$ & 166 & $4.88 \pm 0.46$ & 488 & $4.79 \pm 0.48$ & 471 & $4.70 \pm 0.46$ & 0.000 & 0.175 \\
\hline Hemoglobin (g/dL) & 166 & $14.8 \pm 1.73$ & 488 & $14.7 \pm 1.67$ & 471 & $14.0 \pm 1.65$ & 0.000 & 0.172 \\
\hline Hematocrit (\%) & 166 & $44.1 \pm 4.44$ & 488 & $43.5 \pm 4.25$ & 471 & $41.9 \pm 4.15$ & 0.000 & 0.032 \\
\hline Platelet $\left(\times 10^{3} / \mathrm{mm}^{3}\right)$ & 166 & $252.8 \pm 55.9$ & 488 & $246.8 \pm 51.0$ & 471 & $254.6 \pm 50.7$ & 0.057 & 0.101 \\
\hline \multicolumn{9}{|l|}{ Serum electrolyte } \\
\hline Calcium (mg/dL) & 172 & $9.39 \pm 0.37$ & 489 & $9.35 \pm 0.36$ & 471 & $9.32 \pm 0.37$ & 0.106 & 0.226 \\
\hline Phosphorus (mg/dL) & 172 & $3.57 \pm 0.58$ & 489 & $3.59 \pm 0.57$ & 471 & $3.74 \pm 0.63$ & 0.000 & 0.438 \\
\hline Sodium (mmol/L) & 165 & $141.9 \pm 1.93$ & 485 & $142.0 \pm 2.06$ & 471 & $141.7 \pm 1.79$ & 0.055 & 0.611 \\
\hline Potassium (mmol/L) & 165 & $4.13 \pm 0.34$ & 485 & $4.07 \pm 0.32$ & 471 & $4.04 \pm 0.28$ & 0.006 & 0.044 \\
\hline Chloride (mmol/L) & 164 & $102.9 \pm 2.04$ & 485 & $103.1 \pm 2.03$ & 471 & $103.1 \pm 1.84$ & 0.438 & 0.778 \\
\hline \multicolumn{9}{|l|}{ Serum chemistry } \\
\hline $\mathrm{AST}^{\dagger}(\mathrm{IU} / \mathrm{L})$ & 162 & $24.0 \pm 10.8$ & 476 & $25.3 \pm 12.4$ & 470 & $23.7 \pm 13.5$ & 0.161 & 0.310 \\
\hline $\mathrm{ALT}^{\ddagger}(\mathrm{IU} / \mathrm{L})$ & 162 & $25.1 \pm 16.6$ & 476 & $26.9 \pm 23.7$ & 470 & $23.5 \pm 25.1$ & 0.087 & 0.466 \\
\hline$r-G T P^{\S}(I U / L)$ & 155 & $36.8 \pm 31.6$ & 473 & $39.3 \pm 52.3$ & 466 & $27.5 \pm 28.9$ & 0.000 & 0.240 \\
\hline ALP" (IU/L) & 158 & $180.6 \pm 62.6$ & 475 & $177.6 \pm 51.2$ & 467 & $195.8 \pm 130.3$ & 0.010 & 0.136 \\
\hline Glucose (mg/dL) & 156 & $113.7 \pm 48.5$ & 461 & $105.5 \pm 32.9$ & 446 & $100.1 \pm 20.9$ & 0.000 & 0.038 \\
\hline Total cholesterol (mg/dL) & 159 & $197.6 \pm 36.0$ & 475 & $194.7 \pm 36.0$ & 467 & $190.7 \pm 35.5$ & 0.065 & 0.816 \\
\hline Blood urea nitrogen (mg/dL) & 161 & $13.9 \pm 3.97$ & 473 & $13.1 \pm 3.89$ & 468 & $12.7 \pm 3.59$ & 0.001 & 0.109 \\
\hline Creatinine (mg/dL) & 162 & $0.88 \pm 0.14$ & 473 & $0.89 \pm 0.18$ & 469 & $0.81 \pm 0.19$ & 0.000 & 0.070 \\
\hline Uric acid (mg/dL) & 152 & $5.62 \pm 1.49$ & 460 & $5.51 \pm 1.47$ & 444 & $5.12 \pm 1.45$ & 0.000 & 0.540 \\
\hline
\end{tabular}

"Adjusted for age and sex, using ANCOVA test.

${ }^{\dagger}$ Aspartate transaminase, ${ }^{*}$ Alanine transaminase, ${ }^{5}$ Gamma glutamyl transpeptidase, "Alkaline phosphatase.

hospitalized patients who complained of gastrointestinal symptoms initially reported respiratory symptoms. Thus, the transition to gastrointestinal symptoms such as nausea and abdominal pain could be observed. Gastrointestinal symptoms such as nausea, vomiting, and abdominal pain are thought to be caused by bronchial ciliary action, which releases hydrogen fluoride into the gastrointestinal tract; this could have been caused or exacerbated by psychological stress. In addition, $19.1 \%$ of patients had headache as their chief complaint. Hydrogen fluoride can generate an irritating odor even at concentrations less than $1 \mathrm{ppm}$ $[9,21]$. Furthermore, its potential to cause neurological symptoms may induce headache $[19,22]$.

Fluoride ions are lipophilic and can easily penetrate the body, affecting the body by combining with calcium or magnesium $[6,23]$. Thus, hydrogen fluoride exposure can result in local symptoms such as burns as well as electrolyte abnormalities (e.g., hypocalcemia and hyperkalemia) by changing the concentrations of electrolytes such as calcium, magnesium, and potassium [20,24-28]. In this study, all outpatients had serum calcium within the normal range, and serum calcium did not vary with respect to the distance from the accident site. However, serum potassium was significantly higher in patients closer to the accident site. A study involving hydrofluoric acid burn cases reported that a delayed form of hyperkalemia can occur after exposure to hydrofluoric acid [24,29]. There are 2 possible mechanisms underlying the increase in blood potassium after fluoride exposure. The first is that fluoride ions deactivate $\mathrm{Na}+-\mathrm{K}+$ ATPase to increase extracellular potassium. The second involves the activation of the $\mathrm{Na}+-\mathrm{Ca} 2+$ ion exchanger by fluoride ions, increasing intracellular calcium, which in turn activates calcium-dependent potassium channels to export potassium extracellularly. However, Vohra et al. [30] maintain that hyperkalemia is a phenomenon observed in some cases of hydrofluoric acid exposure and that the relationship between fluoride exposure and hyperkalemia remains unclear. Whether the high potassium concentrations in the patients who were close to the accident site were indeed due to hydrogen fluoride exposure will have to be identified through a detailed investigation in the future. In addition, hematocrit, and serum glucose increased significantly with decreasing distance to the 
accident site, even after adjusting for age and sex. Although it is possible that the increase in serum glucose in patients close to the accident site was due to physical and psychological stress, this also requires detailed study in the future. No lower respiratory tract lesions including pulmonary edema or interstitial pneumonitis were observed in any of the patients. Only 4 out of 48 subjects had abnormal pulmonary functioning test findings; however, a significant difference was not observed with respect to exposure distance. These results demonstrate that the effects of this accident were mostly limited to the upper respiratory tract. Furthermore, it can be assumed that the extent of hydrogen fluoride exposure was not to the point of being absorbed into the blood via the alveoli. However, 3 hospitalized patients had hemoptysis symptoms with findings of bronchitis caused by hydrogen fluoride. In addition, the majority of early patients visiting the emergency room complained of respiratory symptoms and were treated with calcium gluconate inhalation therapy. Thus, the patients exposed to relatively high concentrations of hydrogen fluoride in the initial phase of the accident suffered acute health effects severe enough to cause respiratory damage. Meanwhile, the patients who were victims of the secondary health damage caused by the hydrogen fluoride that subsequently spread through the community suffered acute health effects limited to the upper respiratory tract.

Hydrogen fluoride absorbed into the body has a halflife of 2-9 h in the blood [31], and approximately 60\% is excreted into the urine within $24 \mathrm{~h}$. Meanwhile, $99 \%$ of fluoride compounds not excreted are deposited in the bones as fluorapatite [32], which may lead to bone disease and fluorosis with long-term exposure [23,32-35]. In this study, urine fluoride measurements as a biological index of hydrogen fluoride accumulation in the body were attempted, but meaningful results could not be obtained, because the institution and equipment required for the test were unavailable during the early phase of the exposure. The mean and maximum urine fluoride levels of 66 samples analyzed after 2 weeks were 0.39 and $1.6 \mathrm{mg} / \mathrm{L}$, respectively, both of which are below the threshold value. The threshold values of urine fluoride before and after work are reported to be 3 and $10 \mathrm{mg} / \mathrm{g}$ Cr by the ACGIH and 4 and $7 \mathrm{mg} / \mathrm{g} \mathrm{Cr}$ by the German Research Federation (DFG). Urine fluoride can be affected by various conditions such as water intake and sweating; therefore, creatinine-adjusted values must be calculated. The creatinine-adjusted concentration is calculated by dividing the measured concentration by the urine creatinine concentration. However, this study has a limitation in that adjusted values were not calculated because urine creatinine was not measured. Since the urine creatinine concentration in a typical adult is $1.0-1.6 \mathrm{~g} / \mathrm{L}$, it can be assumed that the urine fluoride levels of the patients in this study were still below the threshold regardless of the fact that adjusted creatinine could not be calculated. Although our estimation of the initial exposure circumstances is limited by late urine sampling in outpatients, it can be assumed that the patients were not significantly exposed to hydrogen fluoride for at least 8 days after the accident.

There are few cases in the literature reporting the health effects of hydrogen fluoride spills in local communities. The most well-documented case in the literature is the hydrogen fluoride spill that occurred in Texas in 1987 [1,36]; although accidents occurred in Oklahoma in 1988 and Mexico in 1991, there were no studies systematically documenting the health effects due to these accidents [37-39]. In the accident that occurred in Texas in 1987, 24 tons of hydrogen fluoride were spilled by an oil company and 3,000 residents within an 800-m radius evacuated the area within $20 \mathrm{~min}$ of the accident. The acute health effects in patients visiting 2 hospitals after the accident were analyzed; the major symptoms reported by the patients included eye irritation (56\%), sore throat (21\%), headache (20.6\%), and shortness of breath (19.4\%), which are similar to the symptoms reported by the patients in the present study [1]. In addition, in a study that followed 10,811 residents 2 years after exposure, the extent of hydrogen fluoride exposure as well as respiratory and eye symptoms exhibited a significant dose-response relationship; furthermore, $30-40 \%$ of the people in the high-exposure group reported respiratory and eye symptoms even after 2 years [36]. These results may have been affected by a potential recall bias. However, the fact that a substantial proportion of subjects in a large-scale follow-up study showed symptoms even after 2 years warrants detailed followup regarding the long-term health effects caused by the Gumi hydrogen fluoride spill as well.

It is essential to evaluate the extent of exposure of every individual in order to precisely identify the health effects following the spill. However, it was impossible to measure direct exposure indices such as the atmospheric hydrogen fluoride concentration with respect to distance or the individual biological exposure index in the present study. Therefore, variables reflecting exposure levels, the timing of hospital visits after the accident, and the distance from the accident site at the time of accident were analyzed as indices that indirectly reflect the exposure level. Regarding the analysis of chief complaints with respect to the distance from the accident site, patients who reported shortness of breath as a chief complaint were closer, while complaints of rhinorrhea and no symptoms were more frequent with increasing distance. The results are concordant with the assumption that more cases of lower respiratory tract symptoms (e.g., shortness of breath) would be observed in patients closer to the accident site because of the exposure to higher concentrations of hydrogen 
fluoride. Meanwhile, the fact that patients who reported rhinorrhea as a chief complaint were far away from the site suggests that hydrogen fluoride exposure is unlikely to cause rhinorrhea. Another index measured in the present study was the timing of hospital visits. Early patients reported shortness of breath and nausea as chief complaints, while late patients reported cough and rhinorrhea. It can be assumed that the early patients, who visited within 3 days, were exposed to high concentrations of hydrogen fluoride, while the late patients, who visited after 4 days, included many patients with upper respiratory tract symptoms such as cough and rhinorrhea in addition to those who reported symptoms caused by low concentrations of hydrogen fluoride due to secondary community contamination.

One unusual aspect of this accident is that the hospital visits exhibited a bipolar distribution. The distribution of patients visiting the hospital showed 3 peaks on the first, eighth, and twelfth day from the accident; the decreases between the eighth and twelfth days are because the ninth and tenth days were weekend days. Thus, it can be assumed that the local residents postponed hospital visits until Monday. Most outpatients started visiting the hospital beginning on the sixth day after the accident, increasing until the twelfth day. Further, 9 out of 12 hospitalized patients were admitted 1 week after the accident. Diluted fluoride may take time to penetrate the tissues, and symptoms may be delayed for $2-3$ days $[27,40]$. In addition, the possibility that the hydrogen fluoride lingered in the local community cannot be excluded. Therefore, it was possible that the patients' symptoms could have developed after a certain delay from the accident or the mild initial symptoms could have worsened over time. However, this likelihood alone cannot explain the fact that the number of outpatients peaked 12 days after the accident and the total number kept increasing for over 16 days. The accident occurred while the season was changing when upper respiratory tract infections are common. Therefore, many residents may have believed upper respiratory tract infection symptoms such as cough, rhinorrhea , and sore throat were related to the hydrogen fluoride. As a consequence, some of the outpatients visiting because of hydrofluoric acid exposure may have, in fact, had unrelated simple upper respiratory tract infection symptoms. The inadequate responses of the government and relevant organizations to the hydrogen fluoride spill may have increased the distrust of residents, and the stimulating news reported daily may have had psychological effects. It will be necessary to consider the psychological and physical effects caused by hydrogen fluoride exposure as well as the relationships between hydrogen fluoride exposure and physical symptoms through detailed assessments of health effects in the future. Only with the assessment of psychological components, the whole effect of hydrogen fluoride exposure on health can be precisely determined [41].

In this study, the data analysis of the acute effects of hydrogen fluoride was limited because of a lack of information about the medical history and exposure level of the early patients. In particular, health effect evaluation and data collection were not performed for the firefighters or public officials on site, whose health risk was of greatest concern. For the early patients who visited the emergency room, medical history surveys were rarely performed and clinical tests could not be performed. Detailed medical history surveys and clinical tests were impossible because of the disaster triage situation. More information could have been gathered and this information could have aided patient care if the medical staff of the Departments of Occupational and Environmental Medicine and Emergency Medicine had cooperated immediately after the accident. Although some atmospheric measurements of the hydrogen fluoride concentration were taken after the spill, they could not be used as an index to clarify the exposure level, as they were neither systematic nor precise. Another limitation of the study is that a considerable amount of time had elapsed before biological samples for the biological exposure index analysis were stored and structured surveys were administered. This study included a total of 1,890 patients, accounting for $15.4 \%$ of the 12,243 people who received treatment for hydrofluoric acid reported by the Gumi Municipal Government until October 21, 2012. Excluding the 5,261 patients who visited the temporary on-site free clinic, the present cohort accounts for $27.0 \%$ of 6,982 patients. The facts that not all of the patients were surveyed and data from only one hospital were analyzed are also limiting factors of this study. This incident warrants the establishment of a system that would enable the medical staff of the Department of Occupational and Environmental Medicine to immediately intervene in situations involving environmental disease due to chemical substances. The outpatient clinic of the Department of Occupational and Environmental Medicine also needs to develop a system to identify the level of exposure of individual patients and be equipped to face large-scale environmental disasters that occur without warning.

The chronic health effects of fluoride and hydrogen fluoride, including skeletal and dental fluorosis, have only been reported among residents living in areas where drinking water contains high concentrations of fluoride or workers who have long-term exposure to fluoride during the aluminum smelting process $[9,32,42,43]$. This accident was a one-time acute spill. On the basis of the symptoms and clinical test results from outpatients, neither the fluoride exposure level nor the exposure period is believed to have been sufficient to cause skeletal or dental fluorosis. However, monitoring the health of exposed residents is 
necessary because of the unique aspects of the Gumi spill and the lack of data about the long-term health effects after acute hydrogen fluoride exposure. Considering that after the spill in Texas in 1987, several cases in the highexposure group had symptoms persisting even after 2 years, the possibility of prolonged physical and psychological symptoms in local community members cannot be ruled out. In particular, the initial investigation was inadequate regarding mental health aspects such as depression and post-traumatic stress disorder. Therefore, continuous follow-up observations on long-term psychological and physical health are necessary.

\section{Conclusion}

The patients exposed to relatively high concentrations of hydrogen fluoride in the initial phase of the accident suffered acute health effects severe enough to cause respiratory damage. Meanwhile, the patients who were victims of the secondary health damage caused by community spread suffered by symptoms limited to the upper respiratory tract such as sore throat, headache, cough, and eye irritation. However, monitoring the health of exposed residents is necessary because of the unique aspects of the Gumi spill and the lack of data about the long-term health effects after acute hydrogen fluoride exposure.

\section{Competing interests}

The authors declare that they have no competing interests.

\section{Authors' contributions}

All authors had access to the data and played a role in writing this manuscript. JSK conceived and designed the study. SYY and SYC were involved in writing the manuscript. SIU and JAK performed the data collection. JSK and JYN performed the statistical analysis, the interpretation of data. KHW had critically revised the manuscript. All authors read and approved the final manuscript.

\section{Acknowledgements}

This work was supported by the Soonchunhyang University Gumi Hospital Environmental Health Center Research Fund.

Received: 16 April 2013 Accepted: 1 August 2013

Published: 19 September 2013

\section{References}

1. Wing JS, Brender JD, Sanderson LM, Perrotta DM, Beauchamp RA: Acute health effects in a community after a release of hydrofluoric acid. Arch Environ Health 1991, 46(3):155-160.

2. Madden EF, Fowler BA: Metal compounds and rare earths. In Environmental and Occupational Medicine. 4th edition. Edited by Rom WN. Philadelphia: Lippincott-Raven Publication; 2007:1085-1087.

3. Lund K, Refsnes M, Ramis I, Dunster C, Boe J, Schwarze PE, Skovlund E, Kelly FJ, Kongerud J: Human exposure to hydrogen fluoride induces acute neutrophilic, eicosanoid, and antioxidant changes in nasal lavage fluid. Inhal Toxicol 2002, 14:119-132.

4. Office of Environmental Health Hazard Assessment: Acute toxicity summary of fluorides including hydrogen fluoride. http://www.oehha.ca.gov.

5. Wong A, Greene S, Robinson J: Hydrofluoric acid poisoning: data from the Victorian Poisons Information Centre. Emerg Med Australas 2012, 24:98-101.

6. Kirkpatrick JJR, Enion DS, Burd DAR: Hydrofluoric acid burns: a review. Burns 1995, 21:483-493.

7. Office of Environmental Health Hazard Assessment: Chronic toxicity summary of fluorides including hydrogen fluoride. http://www.oehha.ca.gov.
8. Centers for Disease Control and Prevention: The National Institute for Occupational Safety and Health: Occupational health guidelines for chemical hazards. http://www.cdc.gov.

9. United States Environmental Protection Agency: Hydrogen fluoride study (Final report). http://www.epa.gov.

10. Gumi City: Report of explosion accident in HUBE Global Inc. (translated by Na JY). http://www.gumi.go.kr.

11. Chae GT, Yun ST, Mayer B, Kim KH, Kim SY, Kwon JS, Kim KJ, Koh YK: Fluorine geochemistry in bedrock groundwater of South Korea. Sci Total Environ 2007, 385:272-283.

12. Ministry of Environment: Standards of soil contamination concern and measures in Soil Environment Conservation Act(translated by Na JY). http://www.me.go.kr (Korean).

13. National Institute of Environmental Research: Report of misunderstanding and the truth about hydrogen fluoride(translated by Na JY). http://www.nier.go.kr (Korean).

14. Waldbott GL, Lee JR: Toxicity from repeated low-grade exposure to hydrogen fluoride-case report. ClinToxicol 1978, 13:391-402.

15. Korea Occupational Safety and Health Agency: Material Safety Data Sheet (MSDS). http://www.kosha.or.kr.

16. United States Environmental Protection Agency: Summery review of health effects associated with hydrogen fluoride and related compounds: health issue assessment. http://www.epa.gov.

17. Lund K, Ekstrand J, Boe J, Søstrand P, Kongerud J: Exposure to hydrogen fluoride: an experimental study in humans of concentrations of fluoride in plasma, symptoms, and lung function. Occup Environ Med 1997, 54:32-37.

18. Bennion JR, Franzblau A: Chemical pneumonitis following household exposure to hydrofluoric acid. Am J Ind Med 1997, 31:474-478.

19. Agency for Toxic Substances and Disease Registry: Toxicological profile for fluorides, hydrogen fluoride and fluorine. http://www.atsdr.cdc.gov.

20. Seo IK, Kim SJ: A case of successful management of inhalation injury caused by hydrofluoric acid poisoning. Korean Soc Emerg Med 2011, 22(1):116. Korean.

21. Centers for Disease Control and Agency for Toxic Substances and Disease Registry: Hydrogen fluoride(HF). http://www.atsdr.cdc.gov.

22. Nabavi S, Sureda A, Nabavi S, Mohammad A, Moghaddam A, Moghaddam H, Moghaddam C: Neuroprotective effects of silymarin on sodium fluoride-induced oxidative stress. J Fluorine Chem 2012, 142:79-82.

23. Hatzifotis M, Williams A, Muller M, Pegga S: Hydrofluoric acid burns. Burns 2004, 30:156-159.

24. Wu ML, Deng JF, Fan JS: Survival after hypocalcemia, hypomagnesemia, hypokalemia and cardiac arrest following mild hydrofluoric acid burn. J Clin Toxicol 2010, 48:953-955.

25. Chapa L, Surani S, Varon J: Management of hydrofluoric acid injury in the emergency department and critical care units. Crit Care Shock 2009, 12:117-119.

26. Gallerani M, Bettoli V, Peron L, Manfredini R: Systemic and topical effects of intradermal hydrofluoric acid. Am J Emerg Med 1998, 16:521-522.

27. Dalamaga M, Karmaniolas K, Nikolaidou A, Papadavid E: Hypocalcemia, hypomagnesemia, and hypokalemia following hydrofluoric acid chemical injury. J Burn Care Res 2008, 29(3):541-543.

28. Blodgett DW, Suruda AJ, Crouch BI: Fatal unintentional occupational poisonings by hydrofluoric acid in the U.S. Am J Ind Med 2001, 40:215-220.

29. Binh TL: Hydrogen fluoride and hydrofluoric acid. In Poisoning \& Drug Overdose. 4th edition. Edited by Kent RO. Singapore: McGraw Hil; 2004:221-224.

30. Vohra R, Velez LI, Rivera W, Benitez FL, Delaney KA: Recurrent life-threatening ventricular dysrhythmias associated with acute hydrofluoric acid ingestion: observations in one case and implications for mechanism of toxicity. J Clin Toxicol 2008, 46:79-84.

31. Sucman E, Bednarr J: Determination of fluoride in plant material using microwave induced oxygen combustion. Czech J Food Sci 2012, 30:438-441.

32. Kim JY, Lim HS, Cheong HK, Lee HK, Kang HS: A study on the change of the bone density among workers exposed to hydrofluoric acid. Korean J Occup Environ Med 1995, 7:120-127. Korean.

33. Ohata U, Hara H, Suzuki H: 7 Cases of hydrofluoric acid burn in which calcium gluconate was effective for relief of severe pain. Contact Dermatitis 2005, 52:133-137.

34. Song YE, Tan H, Liu KJ, Zhang YZ, Liu Y, Lu CR, Yu DL, Tu J, Cui CY: Effect of fluoride exposure on bone metabolism indicators ALP, BALP, and BGP. Environ Health Prev Med 2011, 16:158-163.

35. Bmmml J, Sto $\beta \mathrm{H}$, Zober A: Intoxication following the inhalation of hydrogen fluoride. Arch Toxicol 1984, 56:50-54. 
36. Dayal HH, Brodwick M, Morris R, Baranowski T, Trieff N, Harrison JA,

Lisse JR, Ansari GAS: A community based epidemiologic study of health sequelae of exposure to hydrofluoric acid.

Ann Epidemiol 1992, 2:213-230.

37. United States Environmental Protection Agency: Acute exposure guideline levels for selected airborne chemicals vol. 4. http://www.epa.gov.

38. United States Environmental Protection Agency: Hydrofluoric acid exposures: long-term effects. http://www.epa.gov.

39. Himes JE: Occupational medicine in Oklahoma: hydrofluoric acid dangers. J Okla State Med Assoc 1989, 82:567-569.

40. Dünser MW, Ohlbauer M, Rieder J, Zimmermann I, Ruatti H, Schwabegger AH, Bodrogi F, Huemer GM, Friesenecker BE, Mayr AJ, Lirk P: Critical care management of major hydrofluoric acid burns: a case report, review of the literature, and recommendations for therapy. Burns 2004, 30:391-398.

41. Dayal H, Baranowski T, Li YH, Morris R: Hazardous chemicals: psychological dimensions of the health sequelae of a community exposure in Texas. J Epidemiol Community Health 1994, 48:560-568.

42. Luo KL, Liu YL, Li HJ: Fluoride content and distribution pattern in groundwater of eastern Yunnan and western Guizhou.

China Environ Geochem Health 2012, 34:89-101.

43. Whyte M, Essmyer K, Gannon F, Reinus W: Skeletal fluorosis and instant tea. Am J Med 2005, 118:78-82.

doi:10.1186/2052-4374-25-17

Cite this article as: Na et al:: Acute Symptoms after a Community Hydrogen Fluoride Spill. Annals of Occupational and Environmental Medicine 2013 25:17.

\section{Submit your next manuscript to BioMed Central and take full advantage of:}

- Convenient online submission

- Thorough peer review

- No space constraints or color figure charges

- Immediate publication on acceptance

- Inclusion in PubMed, CAS, Scopus and Google Scholar

- Research which is freely available for redistribution 